\title{
Diagnóstico de Clima Organizacional e Proposições de Endomarketing para Comércio Atacadista: um Relato Técnico
}

\section{Organizational Climate Diagnosis and Endomarketing Propositions for Wholesalers: a Technical Report}

\author{
Lara Coquena da Silva Monzon ${ }^{\mathrm{a}}$; Caroline Gonçalves ${ }^{\mathrm{a}}$; Fernando Thiago ${ }^{\mathrm{a}}$; Suzianny da Silva Mosciaro Ebeling ${ }^{\mathrm{a}}$
}

anniversidade Federal de Mato Grosso do Sul. MS, Brasil.

E-mail:

\begin{abstract}
Resumo
Este estudo teve por objetivo discutir uma proposta para a utilização de ferramentas de endomarketing, visando a melhoria do clima organizacional de uma organização. O primeiro objetivo se marca pela avaliação do clima organizacional da empresa. O clima na organização permite colher percepções dos colaboradores sobre apoio da chefia/organização, recompensa, conforto físico, controle/pressão e coesão entre Colegas, além de possuir correlação positiva com resultados organizacionais. O segundo objetivo é propositivo, e visa o uso racional das estratégias de endomarketing para preencher lacunas encontradas por esta avaliação. Entende-se como endomarketing as estratégias para promover os sentimentos que os colaboradores têm da qualidade dos serviços prestados e produtos da organização e da importância de seus papéis nesta produção, tornando-os chaves no processo de atendimento das necessidades dos clientes. O estudo e as propostas foram feitas em um comércio do tipo atacarejo na cidade de Corumbá/MS. Os dados foram coletados na perspectiva da pesquisa mista, utilizando a Escala de Clima Organizacional de Martins (2008) e entrevista semiestruturada junto aos gestores. Os resultados mostraram um clima organizacional satisfatório e apontam para a combinação positiva das duas vertentes, no âmbito dos estudos em gestão de pessoas, promovendo benefícios para empresa, empregador, e conexão dos colaboradores com os objetivos estratégicos da organização.
\end{abstract}

Palavras-chave: Endomarketing. Clima Organizacional. Atacadista. Varejo.

\begin{abstract}
This study aimed to discuss a proposal to use internal marketing tools to improve organizational climate. The first objective is marked by the assessment of the company's organizational climate. The organizational climate allows us to gather perceptions from employees about support from the management / organization, reward, physical comfort, control / pressure and cohesion among colleagues, in addition to having a positive correlation with organizational results. The second objective is propositional, and aims at the rational use of internal marketing strategies to fill in the gaps found by this assessment. Endomarketing is understood as the strategies to promote the feelings that employees have of the quality of the services provided and products of the organization and the importance of their roles in this production, making them key in the process of meeting the customers needs. The study and proposals were made in a cash-and-carry trade in the city of Corumbá/Brazil. The data were collected from the perspective of the mixed survey, using Organizational Climate Scale (MARTINS, 2008) and a semi-structured interview with the managers. The results showed a satisfactory organizational climate and point to a positive combination of the two aspects in the scope of people management studies, promoting benefits for the company, employer, and connecting employees with the organization's strategic objectives.
\end{abstract}

Keywords: Internal Marketing. Organizational Climate. Wholesaler. Retail.

\section{Introdução}

O município de Corumbá, cenário deste estudo, está localizado na região do Pantanal Sul-matogrossense, em região limítrofe com o país vizinho, a Bolívia, e possui uma população estimada de 110.806 habitantes. Segundo a Relação Anual de Informações Sociais - RAIS (2014) se observa que o número de organizações em Corumbá era de 2.747, gerando o total de 17.036 empregos fixos e com um pessoal ocupado de 15.978 pessoas. De acordo com o último censo do IBGE, em 2010, o salário mensal nesta cidade era de 2.7 saláriosmínimos.

Corumbá é a quarta cidade do Estado de Mato Grosso do Sul em termos populacionais. Ainda, de acordo com o IBGE, o setor do comércio é um dos que mais cresce na cidade, com um aumento no número de estabelecimentos abertos no ano de 2012 estimado em 32,43\% em relação ao setor industriário.

Pensar os negócios de maneira estratégica e buscar se diferenciar dos concorrentes parece ser uma constante nos mercados varejista e atacadista, altamente competitivos. Em um universo cada vez mais pautado pelas tecnologias como estratégia de diferenciação, o olhar para as pessoas nunca deixou (e nem deve deixar) de ser a base dos negócios. Se uma organização torna clara sua missão, visão e valores, focando em seu capital humano, em especial, em seus colaboradores, a estratégia de diferenciação pode estar estabelecida e ser reconhecida por clientes e demais stakeholders. Para Brum (1998), a participação íntegra do funcionário se torna o que 
há de mais importante dentro de qualquer empresa, seja essa de pequeno, de médio ou de grande porte, pois são esses que irão fazer todo o processo funcionar, produção, vendas e atendimento aos clientes, assim como promover a satisfação dos mesmos.

Sob esta perspectiva, atrair o cliente para dentro do negócio, por meio das ferramentas de marketing "externas", como o uso de propagandas, de promoções e de embates com a concorrência, não são mais suficientes para atingir os objetivos da organização. De acordo com Kotler (2003), “o marketing interno deve sobrepor ao marketing externo".

Neste ponto, uma ferramenta estratégica utilizada para estabelecer uma boa relação entre empregador e colaborador, que pode realizar conexões entre interesses pessoais e as necessidades e objetivos estratégicos da organização, é o endomarketing. O termo "endo" é oriundo do grego édon e significa para dentro, logo é um conceito de marketing voltado para o cliente interno.

Se o endomarketing pode despertar nos colaboradores sentimento de importância, de fazer parte de uma equipe e clareza de quais são os objetivos e metas a serem atingidas, parece natural que haja aumento na produtividade, na lucratividade da empresa. Em outras palavras, funcionários satisfeitos, motivados e engajados geram resultados esperados pela empresa.

Dessa forma, interpreta-se que o endomarketing também é capaz de prover melhorias na qualidade de vida no trabalho, na comunicação interna e no clima organizacional. Segundo Peres (2012), o Endomarketing hoje pode ser entendido como um processo estruturado, alinhado ao planejamento estratégico empresarial, visando melhorias da comunicação e buscando a relação com ganhos de produtividade nas organizações. José e Rosa (2014) afirmam que o processo de endomarketing possui dois enfoques básicos: a motivação e a comunicação, aspectos condizentes com os fatores, que influenciam o clima organizacional (KUBO et al., 2015).

Desse modo, a questão que conduz este estudo é: como as ações de endomarketing poderiam influenciar as relações internas entre empregador e funcionários de um estabelecimento comercial?

Como justificativa prática deste estudo a seleção de tal estabelecimento para a pesquisa tem importância, enquanto organização que promove grande empregabilidade na cidade e impacto que o setor de comércio gera na sociedade corumbaense. Do ponto de vista teórico, este estudo propõe aliar as teorias que versam sobre a análise de clima organizacional e o endomarketing.

Para responder à questão posta se procurou investigar um estabelecimento que tivesse acesso ao público interno, optando-se pela investigação em um comércio do tipo atacarejo da cidade de Corumbá/MS, considerado o de maior porte da cidade. $\mathrm{O}$ objetivo geral aqui foi o de investigar o clima organizacional da empresa e combinar uma proposta de utilização do endomarketing como ferramenta estratégica para melhoria do clima organizacional. Para tanto foi necessário conhecer o clima organizacional do objeto de estudo; identificar o uso de ferramentas de endomarketing pela organização; além de diagnosticar situações dentro da organização, em que ações de endomarketing pudessem ser aplicadas.

\section{Material e Métodos}

Quanto aos propósitos mais gerais, esta pesquisa é de caráter exploratório. Segundo Gil (2017), as pesquisas exploratórias têm como propósito proporcionar maior familiaridade com o problema, com vistas a torná-lo mais explícito ou a construir hipóteses. Segundo Vergara (2016), a investigação exploratória, que não deve ser confundida com leitura exploratória, é realizada em área na qual há pouco conhecimento acumulado e sistematizado. Por sua natureza de sondagem não comporta hipóteses que, todavia, poderão surgir durante ou ao final da pesquisa.

Quanto aos meios de investigação, esta pesquisa é de campo e bibliográfica. Segundo Vergara (2016), pesquisa de campo é investigação empírica realizada no local em que ocorre ou ocorreu um fenômeno ou que dispõe de elementos para explicá-lo. Ainda de acordo com Vergara (2016), a pesquisa bibliográfica é o estudo sistematizado desenvolvido com base em material publicado em livros, revistas, jornais, redes eletrônicas, isto é, material acessível ao público em geral. Já segundo Gil (2017), a principal vantagem da pesquisa bibliográfica é o fato de permitir ao investigador a cobertura de uma gama de fenômenos muito mais ampla do que aquela que poderia pesquisar diretamente.

Quanto à natureza desta pesquisa, esta é qualiquantitativa. Em relação às ferramentas de coleta de dados foi aplicado um questionário estruturado de clima organizacional junto aos colaboradores da organização. Além disso, foi realizada observação não participante sobre os instrumentos de endomarketing utilizados pela organização. E por fim realizada uma entrevista semiestruturada com o proprietário da organização e com o gestor das ações de marketing. Segundo Lakatos (2017), a entrevista semiestruturada, também chamada de assistemática, antropológica e livre, em que o entrevistador tem liberdade para desenvolver o tema da interação em qualquer direção que considere adequada.

Os dados foram coletados pela Escala de Clima Organizacional (ECO), validado por Martins (2008). Este possui 63 itens (questões).

A ECO foi composta por cinco fatores, ou seja, multifatorial, os resultados foram apurados por cada fator. O primeiro fator composto por questões de 1 a 21, apoio da chefia. O Segundo fator de itens do 22 ao 34, recompensa. O terceiro fator é composto de itens do 35 ao 47, conforto físico. $\mathrm{O}$ quarto fator, denominado controle e pressão, composto de itens do 48 ao 56. E por fim, o fator número cinco, denominado 
coesão entre colegas, que tem questões entre 57 a 63 (Quadro 1):

Quadro 1 - Denominações, definições, itens integrantes e índices de precisão dos fatores da ECO

\begin{tabular}{|c|c|c|c|}
\hline Denominações & Definições & Itens & $\begin{array}{c}\text { Índices de } \\
\text { Precisão }\end{array}$ \\
\hline $\begin{array}{l}\text { Apoio da chefia } \\
\text { e da organiza- } \\
\text { ção }\end{array}$ & $\begin{array}{c}\text { Suporte afetivo, } \\
\text { estrutural da chefia e da } \\
\text { organização fornecido } \\
\text { aos empregados no } \\
\text { desempenho diário } \\
\text { de suas atividades no } \\
\text { trabalho. } \\
\end{array}$ & $\begin{array}{c}1 \text { ao } \\
21\end{array}$ & 0,92 \\
\hline Recompensa & $\begin{array}{l}\text { Diversas formas de } \\
\text { recompensa usados } \\
\text { pela empresa para } \\
\text { premiar a qualidade, } \\
\text { a produtividade, o } \\
\text { esforço e o desempenho } \\
\text { do trabalhador. }\end{array}$ & $\begin{array}{c}22 \text { ao } \\
34\end{array}$ & 0,88 \\
\hline Conforto Físico & $\begin{array}{l}\text { Ambiente físico, } \\
\text { segurança e conforto } \\
\text { proporcionados } \\
\text { pela empresa aos } \\
\text { empregados. }\end{array}$ & $\begin{array}{c}35 \text { ao } \\
47\end{array}$ & 0,86 \\
\hline $\begin{array}{l}\text { Controle/ } \\
\text { pressão }\end{array}$ & $\begin{array}{c}\text { Controle e pressão } \\
\text { exercidos pela empresa } \\
\text { e pelos supervisores } \\
\text { sobre o comportamento } \\
\text { e desempenho dos } \\
\text { empregados. } \\
\end{array}$ & $\begin{array}{c}48 \text { ao } \\
56\end{array}$ & 0,78 \\
\hline $\begin{array}{l}\text { Coesão entre } \\
\text { colegas }\end{array}$ & $\begin{array}{l}\text { União, vínculos e } \\
\text { colaboração entre os } \\
\text { colegas de trabalho. }\end{array}$ & $\begin{array}{c}57 \text { ao } \\
63\end{array}$ & 0,78 \\
\hline
\end{tabular}

Fonte: Martins (2008).

O Quadro 1 apresenta os cinco fatores da escala de clima organizacional e seus indicadores de precisão. Construída baseada na percepção do colaborador em relação ao ambiente de trabalho com base em variáveis. Valores acima de quatro tendem a indicar um bom clima e valores abaixo de 2,9 tendem a indicar um clima ruim.

O questionário foi entregue aos 70 colaboradores da empresa e respondido por 33 e os dados foram analisados por estatística descritiva e por medidas de tendências central, conforme instruções de Martins (2008).

\section{Resultados e Discussão}

\subsection{O Atacado Fernandes}

Atacadista é o comerciante primariamente envolvido em comprar, adquirir direitos de propriedade e, usualmente, armazenar e manipular bens em grandes quantidades e revendê-los a varejistas ou a usuários industriais e empresariais (CHURCHILL; PETER, 2012). Por esse motivo, os atacadistas podem também ser chamados de distribuidores. É importante que os atacadistas criem valor para os seus stakeholders, sejam esses fornecedores ou compradores, pois o valor criado para estes é uma estratégia de diferenciação da empresa.

Para o sucesso do atacadista, é necessário o desenvolvimento de algumas estratégias ao longo do canal de vendas, estratégias estas relacionadas ao composto de marketing. Criam-se, assim, maneiras de atração tanto dos produtores fornecedores como dos varejistas, para que estes utilizem seus serviços, sejam pelas ações de distribuição, preços, comunicação ou produtos e, assim, se mantêm as relações perenes com estes agentes. Em particular, a criação de valor no canal é uma característica de gestão no mercado atacadista para sobrevivência deste.

Atacadistas e os varejistas são "as grandes estações" de tratamento dos produtores antes de chegarem aos consumidores, e são esses que garantem o fluxo contínuo nos canais de distribuição (ROCHA; SOUZA, 2017). De acordo com Churchill e Peter (2012), os atacadistas podem construir relações duradouras com outros membros do canal para criar valor para esses e para os usuários finais.

Um tipo de negócio mais recente é o chamado "atacarejo", atacadistas que passaram também a realizar vendas diretas para os consumidores, atuando também como varejistas, e estabelecendo preços diferenciados para vendas em menores e maiores quantidades de um mesmo produto, com amparo legal. Como qualquer outra empresa, essa precisa atender e satisfazer as necessidades dos seus clientes, sejam esses pequenos ou grandes varejistas, incluindo também os consumidores finais, propondo-se ao desafio de lidar com os diferentes públicos compradores. O estabelecimento comercial escolhido para este estudo é do tipo atacarejo e pertence à cidade de Corumbá/MS.

Conforme informações extraídas do site institucional (ATACADO FERNANDES, 2019), o histórico da empresa Atacado Fernandes inicia com um de seus proprietários Rubens Fernandes, que chegou à cidade de Corumbá/MS a serviço de uma empresa de consultoria de Campo Grande/ MS e em função de uma vasta experiência no ramo atacadista identificou em Corumbá uma oportunidade de negócio.

O Grupo Fernandes possui quatro lojas na cidade de Corumbá-MS, entre essas três filiais e o mais novo empreendimento do grupo é o Atacarejo ou Atacadão Pantaneiro. O grupo emprega cerca de 500 funcionários na empresa. As lojas estão divididas em pontos estratégicos da cidade. A loja 01, implantada em 2002, na Rua Porto Carrero possui $1.000 \mathrm{~m}^{2}$. Já a segunda filial se localiza na Rua 13 de junho, na região central da cidade, com $2.500 \mathrm{~m}^{2}$. A terceira é no bairro Popular Nova, localizada na parte alta da cidade, uma loja menor, com $900 \mathrm{~m}^{2}$. Logo a quarta loja, o Atacadão Pantaneiro, como assim também denominado, se localiza na parte alta da cidade, no bairro Nova Corumbá, com $5.400 \mathrm{~m}^{2}$, esta possui uma estrutura maior que as demais lojas, pois seu estoque se encontra em um setor separado e específico para o maior controle dos gestores, diferentemente das demais lojas nas quais o estoque se encontra dentro da própria loja.

A qualidade e variedade dos produtos são maiores nas filiais, assim como o público-alvo destas lojas é o consumidor familiar que se difere do Pantaneiro, no qual o foco é em 
pequenos negócios, com produtos de grandes marcas e de alto giro, com embalagens de tamanho maior.

No Pantaneiro, os setores são cerca de dez, divididos em compras, conciliação, administração geral, contabilidade geral, tecnologia da informação geral, fiscalização geral de loja, entre outros. O setor de recursos humanos geral está localizado na loja 02, por questão estratégica da empresa. A depender da loja se encontram de três a quatro funcionários em cada setor. O modelo de departamento das lojas Fernandes é o funcional.

As quatro lojas não possuem um organograma muito claro e pré-definido. No Pantaneiro, a hierarquia está subdividida basicamente em diretores, gerente geral, subgerentes e encarregados. Nas demais lojas, os cargos estão subdivididos em gerentes de loja e encarregados de caixa, a quantidade de funcionários para cada uma destas funções se baseia com o tamanho de cada loja. Em relação aos manuais a empresa não tem definido a padronização de atividades. É passado pelos gerentes o que há de ser feito, como por exemplo, no setor de compras, as funções são de gerir e controlar o estoque, realizar de fato as compras e negociações com os fornecedores, e claro os funcionários deste setor necessitam se preocupar também com as vendas. Em meados de cada mês, os colaboradores deste setor já estão treinados para direcionar as atividades pensando no mês seguinte. O setor de compras está concentrado no Atacadão Pantaneiro, divido assim em três subsetores de compras com dois funcionários em cada um desses, responsável por gerir as compras das quatro lojas.

Segundo o gerente geral do Atacadão Pantaneiro, os produtos são escolhidos de acordo com sua qualidade e sempre trazendo grandes marcas para dentro da loja, pois se nota que há grande procura destas pelos seus clientes. Há outro grupo de clientes que optam pela oportunidade de escolha de produtos similares, mas com um preço mais acessível, em função de um nível de renda da população.

É realizado de forma sazonal o inventário das lojas, por profissionais do próprio Grupo Fernandes. O tempo que decorre entre a solicitação do material e a sua efetiva chegada é relativo, pois vai depender do tipo dos produtos como os produtos alimentícios há a necessidade de pedido, frequentemente, em que demora cerca de sete dias para estar na loja o lote solicitado.

O setor de recursos humanos da empresa Atacado Fernandes se concentra apenas na loja 02 responsabilizando, assim, pela gestão de pessoas das quatro lojas. Este setor possui três colaboradoras, sendo uma a gerente geral, está no cargo há sete anos, e as demais ocupam o cargo de assistente de RH. O modelo de RH adotado pela empresa, nos dias de hoje, é o estratégico, pois realiza os trabalhos integrados com os demais setores e não de forma isolada. Tornando-se, assim, este setor parceiro integrado às estratégias da empresa, unindo as demandas do mercado local com as necessidades humanas características do departamento pessoal.

A empresa conta com sistema de informação para recursos humanos, para assim poder atender as exigências fiscais, contábeis e tributárias. Possui, também, programas de inclusão de portadores de necessidades especiais, neste caso, possui parceria com a APAE (Associação de Pais e Amigos dos Excepcionais). Conta ainda com a prática de inclusão de mulheres e negros em cargos de chefia.

A descrição de cargos não é predefinida e claramente elaborada, de maneira bem simples quem as faz é a superior deste setor. Nota-se a importância de inclusão de funcionários através do programa jovem aprendiz, estes têm o período de um ano de contrato com a empresa, a mesma oferece em paralelo com o trabalho, capacitações no SENAC (Serviço Nacional de Aprendizagem Comercial). No final de cada ano são orientadas as atividades para a contratação de novos aprendizes se mantendo assim um ciclo anual de contratação. Nota-se também a importância por parte da gerência em realizar pesquisa de clima organizacional com periodicidade.

Os colaboradores são avaliados diariamente pelos seus encarregados (responsáveis por cada setor: hortifrúti, padaria, açougue etc.). $\mathrm{O}$ gerente geral recebe os relatórios pelos encarregados ao final de cada dia. Obtendo assim, ao fim de cada mês, o funcionário que mais se destacou e com maiores chances de ter uma promoção.

Em relação aos níveis de absenteísmo, casa supervisor fica responsável em informar as faltas de seus funcionários ao RH, podendo solicitar advertências escritas e verbais. A depender dos números de faltas, o benefício mensal de cesta básica poderá ser cancelado.

A empresa não conta com um plano de carreia estabelecida, nota-se a importância desta pela gerência. Os benefícios oferecidos aos colaboradores são: alimentação, plano de saúde, entre outros.

Segundo o gerente do Atacadista Pantaneiro, o layout desta loja, em específico, foi pensado com base em um estudo realizado por ele próprio, em lojas de atacado na capital do Estado de Mato Grosso do Sul, cidade de Campo Grande-MS. Verificando, assim, como era feita a disposição dos produtos e quais eram as marcas oferecidas nestas empresas. Depois de concluído aquele estudo se decidiu aplicar aqui na cidade de Corumbá/MS. No Pantaneiro, o espaço é amplo e com variedades de produtos orientados aos clientes. Na recepção há um balcão especializado para prestar o atendimento e suporte ao cliente. Há também um caixa de autoatendimento, o próprio cliente passa suas compras no leitor de código de barras, hoje há um funcionário para auxiliá-lo. É mais uma inovação que a empresa traz para seus clientes.

No balcão de atendimento aos clientes, também é realizado o pós-venda. Na loja 2 existe um serviço de compras online, um site da empresa no qual o cliente, que mora fora do país, consegue fazer compras e ser entregue na casa de seu familiar aqui em Corumbá.

Em relação às ações de gestão socioambiental, a empresa possui, em sua loja 04, um sistema de captação de toda a água da chuva, um grande reservatório. Esta não possui um 
programa de responsabilidade social predefinido. Outra ação é a de apoio em festividades tradicionais e locais fornecendo alimentos e demais produtos necessários para a realização destes eventos.

A empresa tem planejamento estratégico para os próximos cinco anos ou mais, que se baseia em se tornar uma empresa ainda mais reconhecida na região, poder atender mais programas sociais, ampliar o espaço da loja 4, inserindo pequenas lojas em seu espaço, tornando assim um shopping algo que a cidade ainda não possui, ampliar a variedade de produtos na loja. O planejamento é feito em nível estratégico, ou seja, pelos gerentes gerais. A atuação da empresa é local.

Os produtos oferecidos são de alta qualidade, pois se trabalha com marcas conhecidas no mercado e produtos vendidos em tamanhos e volumes grandes para atender ao pequeno negociante/varejista. As três filiais têm como foco o consumo familiar, o Pantaneiro o público-alvo são os pequenos comerciantes. Nas lojas são determinadas as linhas de produtos, tanto de primeira linha como de segunda, ou seja, marcas com preço mais acessível, dando poder de escolha para o cliente.

As formas de pagamento aceitas pela empresa são: à vista, crédito ou débito. Para garantir uma margem de lucro a empresa adiciona uma porcentagem aos custos finais de seus produtos, para assim formar o preço final de cada produto, definindo o seu lucro em cada venda.

A empresa possui um setor de atendimento ao cliente direto, para atender suas necessidades, ali como também o pós-venda. A logística dos produtos é feita de acordo com a demanda da empresa, os pedidos são feitos, periodicamente, conforme os produtos que necessitam ser repostos, como por exemplo, os produtos alimentícios diferentemente dos produtos de bazar (vassoura, rodo, pano de chão, flanela, pá...).

A publicidade das lojas Atacado Fernandes é feita em rádio, televisão e jornais, assim como são elaborados folhetos com promoções quinzenais. No Pantaneiro, as promoções são feitas com a escolha de 160 produtos que estarão em oferta, já nas demais lojas 90 produtos que são colocados em oferta. Há uma preocupação com a construção da marca do produto, com base no estudo realizado pelos seus gerentes com foco em estudar os grandes atacados da capital. Atualmente, o Pantaneiro já possui marca própria, para as carnes embaladas a vácuo. Procura-se obter marca própria em médio prazo para os demais produtos. Outra forma de divulgação de seus produtos ocorre por meio de seu site, no qual os clientes podem realizar suas compras sem sair de casa.

\subsection{Diagnóstico de Clima Organizacional}

De acordo com a ferramenta de diagnóstico de Clima Organizacional utilizada, os valores gerais encontrados foram os dispostos no Quadro 2.
Quadro 2 - Diagnóstico de Clima Organizacional

\begin{tabular}{|c|c|}
\hline Fatores & Média \\
\hline Apoio da chefia/organização & 3,52 \\
\hline Recompensa & 3,20 \\
\hline Conforto Físico & 3,80 \\
\hline Controle/Pressão & $-3,66$ \\
\hline Coesão entre Colegas & 3,74 \\
\hline Clima total & $\mathbf{3 , 5 8}$ \\
\hline
\end{tabular}

Fonte: dados da pesquisa.

Observa-se que o clima organizacional é percebido pelos colaboradores participantes como acima da média da escala de medida (média $=3,58$ ), compreendendo um resultado positivo entre os fatores analisados.

Figura 1 - Disposição visual dos resultados do clima organizacional

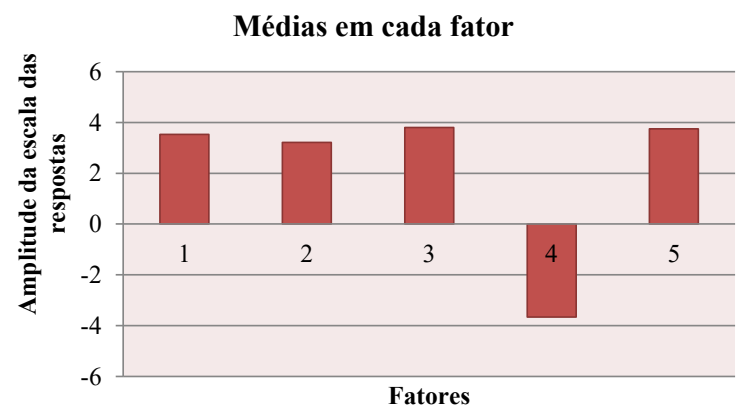

Fonte: dados da pesquisa.

O primeiro fator da escala de clima organizacional, com denominação apoio da chefia e da organização, dentro de uma amplitude de 1 a 5, a média do resultado encontrado foi de 3,52, ou seja, está acima de 2,9, na qual é considerado um bom clima. Com este resultado se pode entender que os colaboradores recebem apoio da chefia nas tomadas de decisões, nas mudanças propostas pela organização, na valorização de opiniões, em elogios pelo bom trabalho realizado, pelas dúvidas esclarecidas, pelo apoio no planejamento das atividades, pelo respeito dentro da organização e pela colaboração na produtividade.

O fator denominado Recompensa, dentro da amplitude de 1 a 5 se nota uma média de 3,20. Está entre 2,9 indicador de um clima ruim e mais próximo de 4 indicador de um clima bom. Nota-se a responsabilidade da empresa em recompensar seus funcionários pelo trabalho realizado com eficiência. Logo a preocupação com a saúde mental e física dos funcionários, deixá-los cientes do motivo pelo qual estão sendo recompensados, valorização de seus esforços, entre outros.

As recompensas podem ser financeiras ou não-financeiras, a primeira está relacionada com o salário do indivíduo e a segunda com segurança, reconhecimento, entre outras.

Muitas vezes o impacto de um elogio/reconhecimento para com um funcionário pode ser maior que o ganho financeiro. A recompensa não-financeira se pode entender também como o bem-estar que o indivíduo sente em pertencer a uma equipe. Este é considerado um conjunto de aspectos positivos, como 
segurança, tranquilidade, conforto, entre outros.

Estes fatores se relacionam à concepção de bem-estar no trabalho como um estado mental positivo pela possibilidade de o trabalhador vivenciar períodos em que emerge dentro desse, de forma interligada, sentimentos positivos promovidos por aspectos presentes no ambiente de trabalho (satisfação), sensações de harmonia entre suas habilidades profissionais e as exigências impostas pelas atividades que realiza (envolvimento com o trabalho) e sentimentos também positivos dirigidos à organização que o emprega (comprometimento organizacional afetivo) (SIQUEIRA; ORENGO; PEIRÓ, 2014, p. 39).

Em termos de Conforto Físico, os resultados apresentaram média 3,80 próximo a 4 que é indicado como um bom clima, nota-se uma boa percepção dos funcionários em relação ao conforto físico que a empresa oferece. Indica que a empresa se preocupa em oferecer um conforto físico para o funcionário, isto é, os funcionários possuem equipamentos de trabalho adequado para realizar as tarefas propostas, o ambiente atende as necessidades físicas do trabalhador (por exemplo, a acessibilidades aos portadores de necessidades especiais é uma das medidas que a empresa adota), o ambiente é arejado, agradável, possui uma boa iluminação, entre outros aspectos.

No fator Controle e Pressão, a análise é realizada de forma diferenciada das demais, pois quanto maior for a média, pior será o clima. Com o resultado da média 3,66 se observa um maior controle e pressão exercida sobre os empregados. Logo, o que pode indicar um resultado alto como este são: as tarefas exigidas devem ser terminadas dentro do prazo, sem haver flexibilidade. A frequência dos colaboradores é controlada com rigor, pressão com relação ao tempo de cada atividade, fiscalização permanente, entre outros.

O fator Coesão entre colegas, com uma média consideravelmente boa. Neste fator se obteve como resultado a média 3,74, próximo a 4, considerando assim um bom clima, ou seja, um funcionário que possua alguma dificuldade ou dúvidas na execução de determinada tarefa, ou ainda assim seja novo na empresa, possui o auxílio dos demais membros da equipe. Há uma integração entre os colegas de trabalho em cada setor, como fora desse.

O colaborador motivado e satisfeito incentiva a si próprio como aos demais membros da organização, melhorando assim o desempenho e a produtividade, que se tornam alinhados para o alcance dos objetivos organizacionais. Para Maximiano (2018), temas que permitem que as pessoas desempenhem seus papéis, de forma motivada, se constituem de fatores de incentivos e estímulos que permitem melhores desempenhos e níveis de satisfação no trabalho. Ainda para este autor, ações como elogios, premiações, benefícios, bônus podem ser utilizados para esta finalidade. Além disso, monitorar e melhorar o clima organizacional acaba por resultar em melhores índices de qualidade de produtos e/ou serviços oferecidos.

\subsection{Proposições de ações de endomarketing fundamentadas no diagnóstico de clima organizacional}

A literatura científica da área de administração tem evidenciado uma correlação positiva entre resultados organizacionais e clima organizacional. Esse pode ser perceptível pelo comportamento das pessoas, assim como pela visão que eles têm da organização, podendo ser favorável ou não (KUBO, et al., 2015). De acordo com Luz (2003), o clima organizacional permite identificar as motivações das pessoas, cultura organizacional, satisfação com o trabalho, planejamento e metas organizacionais, processo decisório, entre outros.

Para Daft (2015), as companhias bem-sucedidas são aquelas que prestam atenção cuidadosa tanto aos valores culturais quanto ao desempenho do negócio. Valores culturais podem energizar e motivar os empregados apelando para ideais superiores e ligando as pessoas ao redor de metas compartilhadas.

No entender deste estudo, avaliar e analisar os resultados do clima organizacional encontrado vai, portanto, além do mero levantamento dos dados, buscando propor sugestões efetivas para melhoria do clima organizacional e das relações entre empregadores e funcionários, utilizando-se das ferramentas de endomarketing, que corroboram com o exposto por Maximiano (op. cit).

Quanto ao objeto analisado, que se trata um o comércio varejista e atacadista da cidade de Corumbá/MS, verifica-se que ao serem ranqueados os fatores do cenário menos favorável para o mais favorável se tem o seguinte ordenamento: (1) Recompensa $(3,20)$; (2) Apoio da chefia/organização $(3,52)$; (3) Controle/Pressão (3,66); (4) Coesão entre colegas $(3,74)$; Conforto físico $(3,80)$, destacando os que precisam de maior interferência, embora todos possam ser incrementados.

Correspondendo ao item "recompensa", que são as diversas formas de recompensar usadas pela empresa para premiar a qualidade, a produtividade, o esforço e o desempenho do trabalhador se podem propor as seguintes ações de Endomarketing para a melhoria de seus índices: eventos com a participação de familiares dos funcionários, Palestras e/ou Convenções, Promoções do tipo gincanas e eventos internos, premiação sobre sugestões de melhoria para a organização, pois estas ações visam recompensar os funcionários pelos trabalhos desenvolvidos, aumentando assim, seu sentimento de pertencimento, de fazer parte de uma equipe, de se sentir valorizado. Práticas que a empresa, todavia, não adota, somente com seus diretores e gestores nas palestras e convenções.

Já para o item "apoio da chefia/organização", que são o suporte afetivo, estrutural da chefia e da organização fornecido aos empregados no desempenho diário de suas atividades no trabalho, se sugere aqui a utilização de: Cartazes informativos e motivacionais, Intranet, Revista interna, porque estas ações têm como objetivo trazer temas variados, 
ressaltando atitudes de colaboradores que fazem diferença, eventos, programas de treinamento, programas corporativos, dicas de desenvolvimento pessoal e profissional, e ter espaços definidos para a comunicação interna corporativa, comunicação interna local e programas interativos, local para publicação de cartazes em diversos formatos, também são um ótimo local para campanhas motivacionais, melhorando assim a percepção dos colaboradores em relação ao ambiente de trabalho, consequentemente, melhorando o clima organizacional da organização. E conforme dados coletados na entrevista com a gestora de Recursos Humanos, estas ações não são praticadas pela empresa, salvo os cartazes informativos de direcionamento de produtos para os clientes.

Tais ferramentas de endomarketing sugeridas corroboram com o proposto por Peres (2012), que indica as seguintes finalidades a cada uma dessas: o Jornal Interno é útil para uniformizar a linguagem, promover encontros, difundir ideias, revelar talentos e motivar as pessoas; Vídeo Jornal segue o mesmo princípio do jornal interno, porém utiliza o recurso do vídeo; poder-se-ia ainda considerar a Feira de Negócios, na qual os próprios colaboradores da empresa têm que montar uma feira (com stands, atrativos etc). O objetivo da Feira de Negócios é fazer com que cada área da empresa apresente os seus serviços/produtos para as outras áreas.

No tocante ao fator "controle/pressão", exercidos pela empresa e pelos supervisores sobre o comportamento e desempenho dos empregados, não se observa a liberdade com relação aos colaboradores expressarem ideias novas, serem mais participativos, compreensão com o não cumprimento das atividades propostas dentro do prazo, bem como flexibilidade com horários que, por algum motivo justificável, o colaborador precisou se ausentar do ambiente de trabalho. Um funcionário, que se sente pressionado, tem afetado seu desempenho e muda a visão que tem da organização, podendo essa não ser favorável, influenciando no clima organizacional.

Sugere-se neste item as seguintes ações: reuniões periódicas com gestores e diretores, Cartazes informativos e motivacionais, programas de treinamento, e dicas de desenvolvimento pessoal e profissional, pois estas ações podem influenciar no convívio e relacionamento dos funcionários com seus superiores, quanto maior o contato, menor controle e a pressão, pois os colaboradores estão diariamente cientes de seu papel dentro da organização.

De acordo com os dados obtidos em entrevista, estas ações não ocorrem na empresa, somente são direcionadas aos funcionários informações sobre os produtos que estão em promoção e não sobre medidas práticas de como agir no ambiente de trabalho. Reuniões periódicas com gestores são de suma importância sobre o lado psicológico do funcionário, orientando como se comportar tanto com os demais colegas, como diante do público, fazendo assim com que o funcionário compreenda as demandas da organização e os motivos da pressão pelo desempenho e pontualidade.

Proporcionar ao colaborador atenção, educação e informação para torná-lo preparado ao atender e satisfazer o cliente externo são funções do endomarketing. Sendo assim, surge a necessidade de as empresas manterem um clima interno favorável, para a conquista de seu funcionário. Segundo Albrecht (1994, p.33):

os empregados não estão convencidos da qualidade dos serviços prestados pela empresa e da importância de seus papeis nesta produção, não há nada na terra que os torne dispostos a vendê-los para seus clientes.

De acordo com o item "coesão entre colegas", que são o conjunto da união, de vínculos, de integração, da colaboração entre os colegas de trabalho, relação de parceria e amizade, auxílio nas atividades ao receber um colaborador novo. Neste item são sugeridas as seguintes ações: grife interna (camisetas, bonés e acessórios com a marca da empresa); uniformes em datas comemorativas (uma ação que a empresa já pratica, já a grife Interna, todavia, é uma ação que a empresa não pratica, segundo dados da entrevista com a gestora de Recursos Humanos); além da integração entre colaboradores via comemoração dos aniversariantes do mês; eventos fechados para os colaboradores em datas comemorativas (dia de São João, dia dos pais, dia das mães, natal, entre outros). Além disso, jornais internos e ações em vídeo internas podem motivar o colaborador e fazê-los se conhecerem melhor.

Considerando que o aspecto "conforto físico" teve melhor avaliação entre os respondentes, e que leva em consideração o ambiente físico, a segurança e o conforto proporcionados pela empresa aos empregados. Recomenda-se a utilização da seguinte ação de endomarketing: manuais técnicos de uso de espaços, pois um espaço físico agradável, arejado, com uma iluminação adequada e as ferramentas necessárias para cada trabalhador de cada setor; um ambiente que ofereça um conforto em relação a atender as necessidades especiais de colaboradores que possuam alguma deficiência física com o objetivo de inclusão no ambiente de trabalho; uniformes confortáveis e bonitos; um espaço para descanso nos intervalos bem decorado e agradável.

\section{Conclusão}

O presente estudo teve como objetivos realizar um diagnóstico de clima organizacional e propor ações de endomarketing para uma organização atacadista do município de Corumbá-MS. Dentro dos parâmetros analisados foi possível identificar que a empresa estudada possui um bom clima organizacional satisfatório e que a empresa já adota algumas ações de endomarketing, ainda que de maneira nãoconsciente.

Nesse sentido, a contribuição deste trabalho permitiu testar os conhecimentos teóricos consolidados a uma situação real, desenvolvendo proposições em termos de ações de endomarketing, baseadas nas percepções dos colaboradores acerca dos fatores de clima organizacional.

Em termos gerenciais, o artigo apresenta um trabalho técnico, no qual se realizou diagnóstico organizacional e 
proposições para ações possíveis de serem utilizadas pela organização.

Como é comum em pesquisas como estas, algumas foram as dificuldades encontradas, mas a principal dessas foi a indisponibilidade de tempo de/e acesso aos entrevistados. Dada a quantidade de funcionários da organização e notandose que apenas alguns foram disponibilizados para responder a pesquisa, isso se tornou uma limitação operacional do trabalho e possível causa de viés, se fosse este estudo realizado novamente com todos os funcionários. Em termos de limitações metodológicas, esta pesquisa foi realizada apenas em uma organização, não sendo passível de generalizações.

Como sugestões para pesquisas futuras se propõem novos estudos comparativos com os demais comércios atacadistas da região, além de estudos quantitativos para verificar correlações entre fatores de endomarketing e clima organizacional. Para este estudo, as teorias pareceram se relacionar e se tornarem ferramentas com transposição prática ao objeto quando se complementam. Se por um lado a avaliação do clima identifica os pontos positivos e negativos percebidos pelos colaboradores, por outro lado, as ferramentas de endomarketing podem contribuir para a melhoria deste clima, dos anseios da organização e do bem-estar de seus colaboradores.

\section{Referências}

ALBRECHT, K. Serviços interno: como resolver a crise de liderança no gerenciamento de nível. São Paulo: Pioneira, 1994.

ATACADO FERNANDES. Institucional: quem somos. 2019. Disponível em https://atacadofernandes.com.br/institucional/ Acesso em:15 mar. 2020.

BRUM, A.M. Endomarketing como estratégia de gestão: encante seu cliente interno. Porto Alegre: L\&PM, 1998.

CHURCHILL, G.A.; PETER, J.P. Marketing: criando valor para os clientes. São Paulo: Saraiva, 2012.
DAFT, R.L. Administração. São Paulo: Cengage Learning, 2015. GIL, A.C. Como elaborar projetos de pesquisa. Rio de Janeiro: Atlas, 2017.

JOSÉ, B.L.C.S.; ROSA, A.T.R.O. O endomarketing como ferrmamenta estratégica de gestão. Rev. Ciênc. Gerenciais, v.16, n.24, p.145-159, 2012. doi: https://doi.org/10.17921/1415$6571.2012 \mathrm{v} 16 \mathrm{n} 24 \mathrm{p} \% 25 \mathrm{p}$.

KUBO, E.K.M. et al. Frankenstein e o clima organizacional: Estudo bibliográfico sobre um construto indefinido. Rev. Int. Investig. Ciência. Soc., v.11, n.1 p.35-54, 2015. doi: https://doi. org/10.18004/riics.2015.julio.35-54.

LAKATOS, E. M. Metodologia cientifica. Rio de Janeiro: Atlas, 2017.

LUZ, R. Clima organizacional. Rio de Janeiro: Qualitymark, 2003.

MARTINS, M.C.F. Clima organizacional. In: SIQUEIRA, M.M.M. Medidas do comportamento organizacional. Porto Alegre: Artmed, 2008.

MAXIMIANO, A.C.A. Teoria geral da administração: da revolução urbana à revolução digital. São Paulo: Atlas, 2018.

PERES, T.C.O. Ferramentas do endomarketing para avaliar e propor melhorias no clima organizacional de uma biblioteca universitária pública. Rev. Dig. Bibl. Ci. Inf., v.9, n.2, p.12-24, 2012. doi: http://dx.doi.org/10.20396/rdbci.v9i2.1907.

ROCHA, M.; SOUZA, J. Canais de distribuição e geomarketing. São Paulo: Saraiva, 2017.

SEBRAE. Desenvolvimento econômico territorial. Mato grosso do Sul. Corumbá-Pantanal. Disponível em: https://m. sebrae.com.br/Sebrae/Portal\%20Sebrae/UFs/MS/Anexos/ Mapa\%20Oportunidades/Mapa\%20de\%20Oportunidades $\% 20$ CORUMB\%C3\%81.pdf Acesso em: 1 abr. 2021.

SIQUEIRA, M.M.M.; ORENGO, V.; PEIRÓ, J.M. Bem-estar no trabalho. in: siqueira, m.m.m. (org.). Novas medidas do comportamento organizacional: ferramentas de diagnóstico e de gestão. Porto Alegre: Artmed, 2014. p.39-51.

VERGARA, S.C. Projetos e relatórios de pesquisa em administração. São Paulo: Atlas, 2016. 